\title{
Anhang 2 \\ Chronologie von Christopher Hansteens Russlandreise im Vergleich mit der Reise Alexander von Humboldts
}

Die Chronologie der Reise von Christopher Hansteen folgt den „Resultaten magnetischer, astronomischer und meteorologischer Beobachtungen auf einer Reise nach dem östlichen Sibirien in den Jahren 1828-1830“ (Hansteen/Due 1863, S. 33-49). Die Chronologie von Humboldts Reise ist der Zusammenstellung in „Alexander von Humboldt. Briefe aus Russland 1829“ entnommen (Briefwechsel Humboldt-Russland 2009, S. 45-52). Die Schreibweise der Orte richtet sich nach der jeweiligen Quelle (vgl. Kap. Geographische Namen). Die Datumsangaben sind die des Gregorianischen Kalenders, d. h. des Kalenders neuen Stils. Angegeben werden die Daten, die in den genannten Quellen belegt sind.

\begin{tabular}{|c|c|c|}
\hline \multicolumn{2}{|c|}{ Reise von Christopher Hansteen } & \multirow[t]{2}{*}{ Reise von Alexander von Humboldt } \\
\hline 22. Juni bis 6 . Juli 1828 & St. Petersburg, & \\
\hline 13. Juli 1828 & Novgorod Weliki & \\
\hline 18. Juli 1828 & Twer & \\
\hline 21. bis 29. Juli 1828 & Moscwa & \\
\hline 30. Juli 1828 & Bogorodsk & \\
\hline 3. August 1828 & Murom & \\
\hline 6. bis 7. August 1828 & Nischni Novgorod & \\
\hline 16. August 1828 & Kazan & \\
\hline 26. August 1828 & Perm & \\
\hline 2. September 1828 & Jekaterinburg & \\
\hline 7. September 1828 & Nischni Tagilsk & \\
\hline 14. September 1828 & Bogoslovskoie & \\
\hline 24. September 1828 & Jekaterinburg & \\
\hline 4. Oktober 1828 & Tiumen & \\
\hline 9. bis 29. Oktober 1828 & Tobolsk & \\
\hline 23. Dezember 1828 & Kainsk & \\
\hline 28. Dezember 1828 & Kolywan & \\
\hline 31. Dezember 1828 & Tomsk & \\
\hline \multicolumn{3}{|l|}{ bis 2 . Januar 1829} \\
\hline 7. bis 8. Januar 1829 & Narym & \\
\hline 14. Januar 1829 & Tomsk & \\
\hline 19. Januar 1829 & Atschinsk & \\
\hline 23. Januar 1829 & Krasnojarsk & \\
\hline 29. Januar 1829 & Kansk & \\
\hline 9. Februar 1829 & Irkutsk & \\
\hline 14. Februar 1829 & Werchne-Udinsk & \\
\hline 16. bis 17. Februar 1829 & Troisko Sawsk & \\
\hline
\end{tabular}


Reise von Christopher Hansteen

21. Februar 1829

24. Februar 1829

26. Februar 1829

4. März bis 14 . Mai 1829

Irkutsk

19. bis 21. Juni 1829

Jeniseisk

7. Juli 1829

Turuchansk

8. bis 31. August 1829

Krasnojarsk

10. September 1829

Tomsk

27.-28. September 1829 Barnau

5. bis 7. Oktober 1829 Zmeinogorsk

* Übernachtung.

** Humboldts 60. Geburtstag am 14. September.
Reise von Alexander von Humboldt

$\begin{array}{ll}\text { 1. bis 20. Mai } 1829 & \text { St. Petersburg } \\ \text { 21. Mai } 1829 & \text { Novgorod } \\ \text { 30. Mai } 1829 & \text { Murom } \\ \text { 4. bis 7. Juni } 1829 & \text { Kasan } \\ \text { 13. Juni } 1829 & \text { Perm } \\ \text { 15. Juni } 1829 & \text { Ekaterinburg }\end{array}$

27. bis 30. Juni $1829 \quad$ Nižni Tagil

3. Juli 1829

6. Juli 1829

Bogoslovsk

Ekaterinburg

19. Juli 1829

20. Juli 1829

27. Juli 1829

Tjumen

Tobolsk

Tara

4. August 1829

Barnaul

7. August 1829

Kolyvan

9. August 1829

Zmeinogorsk

Ust'-Kamenogorsk

Ust'-Buchtarma

Krasnojarsk*

Baty

Ust'-Buchtarma

Ust'-Kamenogorsk

Semipalatinsk

Omsk

3.-6. September 1829 Miass

7.-10. September 1829 Slatoust

13.-16. September 1829 Miass **

19. September 1829 Orsk

26. September 1829 Orenburg

30. September 1829 Samara

5. Oktober 1829 Saratov

10. Oktober 1829 Sarepta 


\begin{tabular}{|c|c|c|c|}
\hline \multicolumn{2}{|c|}{ Reise von Christopher Hansteen } & \multicolumn{2}{|c|}{ Reise von Alexander von Humboldt } \\
\hline 11. Oktober 1829 & Semipalatinsk & 12.-21. Oktober 1829 & Astrachan \\
\hline \multirow[t]{4}{*}{ 19. bis 20. Oktober 1829} & Omsk & & \\
\hline & & 24. Oktober 1829 & Sarepta \\
\hline & & 28.-29. Oktober 1829 & Voronež \\
\hline & & 1. November 1829 & Tula \\
\hline \multirow[t]{2}{*}{ 2. November 1829} & Troitzk & 3.-9. November 1829 & Moskau \\
\hline & & 13. November 1829 & St. Petersburg \\
\hline 14. November 1829 & Ufa & & \\
\hline 19. November & Orenburg & & \\
\hline bis 9. Dezember 1829 & & & \\
\hline 21. Januar 1830 & Uralsk & & \\
\hline 12. Februar 1830 & Tschernoi Jarr & & \\
\hline 16. bis 21 . Februar 1830 & Astrachan & & \\
\hline 1. März 1830 & Tschernoi Jarr & & \\
\hline 5. März 1830 & Zarizin & & \\
\hline 9. März 1830 & Saratow & & \\
\hline 14. März 1830 & Pensa & & \\
\hline 17. März 1830 & Saransk & & \\
\hline 24. März 1830 & Murom & & \\
\hline 5. April 1830 & Torschok & & \\
\hline 20. April 1830 & St. Petersburg & & \\
\hline 13. Mai 1830 & Wiburg & & \\
\hline 24. Juni 1830 & Christiania & & \\
\hline
\end{tabular}

